\title{
CES
}

COOPERATIVISMO E ECONOMÍA SOCIAL

Núm. 40 (2017-2018), páxs. 355-363

ISSN: 1130-2682

\section{LAS MICROEMPRESAS COOPERATIVAS Y LAS COOPERATIVAS RURALES DE CASTILLA-LA MANCHA}

\author{
THE COOPERATIVE MICROENTERPRISES AND THE \\ RURAL COOPERATIVES IN CASTILLA-LA MANCHA
}

\author{
María Luisa CaBello LóPeZ*
}

Abogada del Ilustre Colegio Provincial de Abogados de Lugo. Dirección de correo electrónico: cabelloabogados@hotmail.com 


\title{
RESUMEN
}

La creciente importancia, tanto en volumen como económicamente, de las microempresas cooperativas y de las cooperativas rurales, y el interés del legislador de Castilla-La Mancha por promocionar un modelo de empresa en el que los objetivos económicos y empresariales se integren con otros de carácter social, consiguiendo de esta forma un crecimiento económico sostenible y socialmente responsable, han llevado a la aprobación de la Ley 4/2017, de 30 de noviembre, que regula de forma específica el régimen jurídico de estas figuras societarias, y se aplica de forma supletoria a la Ley Autonómica de Cooperativas. Palabras Clave: Sociedades cooperativas, microempresa cooperativa, cooperativa rural, Registro Autonómico.

\begin{abstract}
The growing importance, both in volume and economically, of cooperative microenterprises and rural cooperatives, and the interest of the legislator of Castilla-La Mancha to promote a business model in which economic and business objectives are integrated with others of a social nature, thus achieving a sustainable and socially responsible economic growth, have led to the approval of Law 4/2017, of November 30, which specifically regulates the legal regime of these corporate figures, and is applied in a supplementary manner to the Autonomic Law of Cooperatives.
\end{abstract}

KeY WORDS: Cooperative societies, cooperative microenterprises, rural cooperatives, Regional Registration. 
SUMARIO: 1 . PLANTEAMIENTO GENERAL. 2. LA MICROEMPRESA COOPERATIVA 3. LA COOPERATIVA RURAL.

CONTENTS: 1. GENERAL APPROACH. 2. THE COOPERATIVE MICROENTERPRISE. 3. THE RURAL COOPERATIVE.

\section{Planteamiento general}

$\mathrm{C}$ onsiderando a las sociedades cooperativas como uno de los pilares del desarrollo económico y social de Castilla-La Mancha, la Administración Autonómica ha entendido, y reflejado en su Legislación, que la promoción de estas entidades debe conformar un elemento clave para favorecer y potenciar un desarrollo económico sostenible y socialmente responsable. No en vano se trata de un modelo de empresa en el que los objetivos económicos y empresariales se integran con otros de carácter social, consiguiendo de esta forma un crecimiento económico basado en el empleo, la equidad social y la igualdad.

Es en este contexto donde debe enmarcarse la aprobación de la Ley 4/2017, de 30 de noviembre, "de Microempresas Cooperativas y Cooperativas Rurales de Castilla-La Mancha y por la que se modifica la Ley 11/2010, de 4 de noviembre, de Cooperativas de Castilla-La Mancha"1; norma que trata de dar respuesta a determinados proyectos cooperativos que hasta ahora han visto limitadas sus posibilidades de desarrollo, en parte debido a la necesaria amplitud de la regulación legal de la figura cooperativa. Se trata, en concreto, de establecer un estatuto jurídico de determinadas iniciativas empresariales dentro de la figura de la sociedad cooperativa, caracterizadas por su reducido tamaño, especialmente en cuanto al número de personas que pretendan constituirlas, conformándose un modelo de empresa ágil y eficaz, tanto en lo que se refiere a su regulación jurídica como a simplificación administrativa.

Ante esta constatada realidad, la Ley 11/2010, previó, como novedad, la posibilidad de creación de la llamada sociedad microempresa cooperativa, especialidad de las cooperativas de trabajo asociado y de explotación comunitaria de la tierra, con la finalidad, no de regular una nueva clase de cooperativa, sino de adaptar la legislación cooperativa a estas entidades cooperativas menores, simplificando su regulación y adecuándola, en la medida de lo posible, a las necesidades de su

1 Diario Oficial de Castilla-La Mancha núm. 237, del 11 de diciembre de 2017; Boletín Oficial del Estado núm. 23, del 26 de enero de 2018. 
reducido tamaño, para que ningún proyecto empresarial, por reducido que fuese, quedase sin cobertura jurídica de naturaleza cooperativa.

En la misma línea, igualmente se ha pretendido dar respuesta a la diversificación de las economías rurales, que han dejado de ser sinónimo de agricultura y han experimentado un importante desarrollo empresarial, que excede de las posibilidades de las cooperativas agrarias tradicionales. Efectivamente, también en la Ley 11/2010 se previó como novedad la posibilidad de creación de la llamada cooperativa rural, que permitiría a las cooperativas agrarias diferenciar y dimensionar sus actividades y ampliar su objeto social a otras nuevas potencialmente demandadas, a través del sistema legal de secciones con regulación societaria y económica diferenciada.

Siendo así, lo cierto es que desde la entrada en vigor de la Ley 11/2010 han cobrado mayor importancia, tanto en volumen como económicamente, las citadas especialidades que fueron incipientemente reguladas, y si bien ya se preveía en la citada Ley su posterior desarrollo reglamentario, debido a la mayor significación de ambas figuras, unido al impulso que se quiere otorgar a las mismas, se ha considerado más adecuado a dichos fines que una Ley regule de forma específica su régimen jurídico.

Asimismo, con esta nueva Ley, la que ahora nos ocupa, se llevan a cabo algunas modificaciones puntuales de la Ley 11/2010 consistentes, en esencia, en la supresión de trámites administrativos para la constitución y modificación de los estatutos sociales de la cooperativa; en la simplificación del procedimiento de renovación de los miembros del órgano de administración; se mejora la regulación de la descalificación, de las operaciones con terceros y del Fondo de Reserva Obligatorio y el Fondo de Reserva Voluntario; se introduce la disolución, liquidación y extinción simultánea de la cooperativa; se introducen nuevos supuestos que permiten cumplir con el requisito del depósito de las cuentas anuales; se eliminan las referencias de dicha Ley a las microempresas cooperativas y a las cooperativas rurales; se regula de forma transitoria la suspensión del derecho de voto para los miembros socios no productores en las cooperativas que cuenten con el reconocimiento de organización de productores; se elimina el requisito de la publicidad en prensa de las modificaciones estatutarias; y se introducen criterios de desempate para las cooperativas de iniciativa social sin ánimo de lucro (disposición final primera).

Pues bien, la Ley 4/2017 se estructura en una exposición de motivos y tres títulos. Los títulos II y III se dividen, cada uno de ellos a su vez, en cuatro capítulos. Consta de 29 artículos, tres disposiciones adicionales, cuatro disposiciones transitorias y tres disposiciones finales. 


\section{LA MICROEMPRESA COOPERATIVA}

Tras el título I, en el que se establecen las disposiciones generales de la Ley, el título II se dedica a la microempresa cooperativa, regulándose en el mismo, a lo largo de cuatro capítulos, una serie de disposiciones generales (arts. 3 a 5), los socios de la entidad (arts. 6 a 9), sus órganos sociales (arts. 10 a 12), y su régimen económico (arts. 13 a 18).

La microempresa cooperativa se define como "una sociedad cooperativa de primer grado perteneciente, con carácter exclusivo, a las clases de cooperativas de trabajo asociado y de explotación comunitaria de la tierra", configurándose como una modalidad de dichas clases en razón de su número de socios (art. 3). Deberá incluir necesariamente en su denominación los términos "sociedad microempresa cooperativa de Castilla-La Mancha" o su abreviatura "S. Microcoop. de C-LM" (art. 4).

Podrán constituirse como microempresas cooperativas tanto las sociedades cooperativas de nueva constitución como aquellas ya constituidas a la entrada en vigor de la Ley, que previa adaptación de sus estatutos, cumplan los requisitos establecidos en la misma. La microempresa cooperativa se constituirá mediante escritura pública y adquirirá personalidad jurídica previa inscripción en la unidad competente del Registro de Cooperativas de Castilla-La Mancha. Este Registro tramitará, de forma abreviada, la inscripción de la constitución de microempresas cooperativas, en el plazo del día hábil siguiente a aquel en que todos los documentos necesarios para su constitución obren en la sede de la unidad registral competente (art. 5).

En el capítulo II, "De las socias y socios", se indica que las microempresas cooperativas estarán constituidas por un mínimo de dos y un máximo de diez socios ordinarios, pudiendo contar con personas socias colaboradoras, en los términos previstos en la legislación cooperativa de Castilla-La Mancha (art. 6). Asimismo, la microempresa cooperativa de trabajo asociado, durante un plazo máximo de siete años desde la fecha de su constitución, podrá contratar a personas trabajadoras por cuenta ajena en cualesquiera de sus modalidades legalmente establecidas; durante ese mismo plazo, el número de personas trabajadoras por cuenta ajena con contrato indefinido no podrá exceder de cinco, salvo que por necesidades objetivas de la microempresa se vea obligada a superar esa cifra (art. 8).

La microempresa cooperativa de trabajo asociado que hubiera optado en sus estatutos sociales por el régimen especial de trabajadores autónomos para sus socios trabajadores, podrá establecer estatutariamente la obligación del pago por la propia cooperativa de las cuotas de la Seguridad Social de los socios durante su periodo activo en la misma, sin perjuicio del sometimiento a la normativa reguladora del régimen correspondiente de la Seguridad Social (art. 7). 
Finalmente, en el artículo 9 se prevé la posibilidad del ejercicio de un derecho de adquisición preferente para los trabajadores no socios y, en su defecto, para los socios trabajadores, a fin de adquirir la participación social que quiera transmitir un socio. En todo caso, transcurridos tres meses a contar desde la comunicación del propósito de transmisión sin que se hubieran ejercitado los derechos de adquisición preferente, quedará libre la persona socia para transmitir las participaciones de su titularidad.

Los órganos sociales, regulados en el capítulo III, con los que debe contar necesariamente la microempresa cooperativa son la asamblea general, donde se integran la totalidad de las personas socias, y el órgano de administración. Se tenderá en ambos a la participación equilibrada de mujeres y hombres (art. 10).

La asamblea general, como órgano soberano de la microempresa cooperativa, será competente para adoptar acuerdos en materia de gestión ordinaria, y para deliberar y decidir mediante votación todos los asuntos propios de la sociedad. Estatutariamente se podrá prever que se convoque por medios electrónicos o mediante anuncio publicado en la página web corporativa de la cooperativa, en el caso de disponer de ella. No será necesaria la convocatoria si, estando presentes todas las personas socias de la microempresa cooperativa, aceptan por unanimidad la celebración de la asamblea y los asuntos a tratar en ella.

En la asamblea general, cada persona socia tendrá un solo voto, con independencia del capital social que hubiere suscrito y desembolsado. El voto de las personas socias colaboradoras, si las hubiere, será un voto ponderado proporcional a la cuantía de sus participaciones sociales, sin que la suma total de los derechos de voto de éstos en la asamblea general pueda exceder, en ningún caso, del treinta por ciento de los votos presentes y representados en cada votación asamblearia (art. 11).

La administración de la microempresa cooperativa podrá confiarse, alternativamente, a un administrador único, a dos o más administradores solidarios o mancomunados, o a un órgano colegiado denominado consejo rector, siendo este órgano de administración quien ostenta la representación de la cooperativa y el encargado de la gestión ordinaria, dirección y administración de la misma. Los estatutos sociales determinarán el modo concreto de organizar la administración y ejercer la representación de la sociedad, o bien contemplarán las distintas posibilidades de administración y representación, en cuyo caso corresponderá a la asamblea general, la facultad de optar alternativamente por cualquiera de ellos, sin necesidad de modificación estatutaria, pero elevando el acuerdo a escritura pública e inscribiéndolo en el Registro de Cooperativas de Castilla-La Mancha.

El órgano de administración, salvo disposición contraria de los estatutos sociales, estará siempre formado por personas socias trabajadoras de la microempresa cooperativa. El plazo de duración del cargo de órgano de administración, cual- 
quiera que sea la forma elegida para su organización, será de seis años, pudiendo ser reelegidos. Ello no obstante, los estatutos sociales podrán establecer que el mandato del órgano de administración, con independencia de su composición, sea con carácter indefinido. Todo ello sin perjuicio del derecho de destitución que acuerde ejercer la asamblea general (art. 12).

Por último, en el capítulo IV del título II, "Del régimen económico", se dispone que "el capital social mínimo con el que puede constituirse una microempresa cooperativa no será inferior a 3.000 euros y deberá estar íntegramente suscrito y desembolsado, al menos, en un cincuenta por ciento. El resto del capital social deberá estar desembolsado en un plazo máximo de dos años".

Asimismo, el importe total de las participaciones sociales cooperativas cuya titularidad ostenta cada socio ordinario, bien sean obligatorias o voluntarias, en ningún caso podrá exceder del cincuenta por ciento del capital social, salvo que se trate de socios colaboradores. En este caso, aun cuando no sea de aplicación la limitación máxima indicada, podrá fijarse en los estatutos sociales el montante máximo de suscripción individual de capital social que se estime conveniente (art. 13). La asamblea general determinará anualmente el valor nominal de las participaciones obligatorias de los nuevos socios, así como las condiciones y plazos para su desembolso (art. 14).

Tras unas previsiones referidas a los resultados del ejercicio (art. 15), al destino de los fondos y reservas (art. 16), y al depósito y auditoría de las cuentas anuales (art. 17), finaliza el capítulo IV poniendo de manifiesto que, por regla general, la microempresa cooperativa quedará disuelta y entrará en liquidación por las mismas causas previstas para toda cooperativa en el artículo 110 de la Ley 11/2010, con dos obvias excepciones: a) la causa relativa a la reducción del número de socios por debajo del mínimo legal ha de tener en cuenta las particularidades al respecto de la microempresa cooperativa; y b) la concerniente a la paralización o inactividad de alguno de sus órganos sociales necesarios o la no realización de la actividad cooperativizada, bastará que se desarrolle durante un año de forma continuada, frente a los dos que se exigen con carácter general (art. 18).

\section{LA COOPERATIVA RURAL}

El título III se dedica a la cooperativa rural, regulándose en el mismo, a lo largo de cuatro capítulos, una serie de disposiciones generales (arts. 19 a 21), las personas y entidades socias (art. 22), sus órganos sociales (art. 23), y sus secciones (arts. 24 a 29).

Se define la cooperativa rural como "una clase de cooperativa que teniendo domicilio social en municipios de Castilla-La Mancha con una población igual o inferior a 15.000 habitantes, asocia a personas físicas o jurídicas y tiene por objeto la realización de actividades y prestación de servicios que mejoren econó- 
mica, social y técnicamente a la propia cooperativa, a las personas y entidades socias de la misma o a las terceras personas de su entorno social y ayuden a la dinamización, el desarrollo, la transformación y la generación de valor en el medio rural, aumentando la calidad de vida y la igualdad de oportunidades de las personas vinculadas a la cooperativa, fomentado el desarrollo sostenible del medio rural".

Para el cumplimiento de su objeto social desarrollarán, al menos, dos de las actividades económicas o sociales que sean propias de cualquier otra clase de cooperativas de las reguladas en la Ley 11/2010, siempre que las mismas se refieran a actividades agroalimentarias, explotación comunitaria de la tierra, servicios educativos, culturales, asistenciales, de iniciativa o de integración social, actividades de consumo, turismo rural, ocio y tiempo libre, acciones medioambientales, energéticas, nuevas tecnologías, protección de la dependencia y/o cualesquiera otras actividades de igual o similar naturaleza, que redunden en beneficio del medio rural (art. 19).

Las cooperativas rurales incluirán necesariamente en su denominación social la mención "Sociedad Cooperativa Rural de Castilla-La Mancha" o "S. Coop. Rural de C-LM" (art. 20), y podrán realizar libremente las actividades y servicios cooperativizados previstos en sus estatutos con terceras personas no socias sin limitación porcentual alguna (art. 21).

Según el artículo 22, pueden ser personas y entidades socias de las cooperativas rurales cualquier persona física o jurídica, pública o privada, incluyendo otras cooperativas, que precisen de los bienes y servicios que se presten o gestionen por la cooperativa. Las personas y entidades socias lo podrán ser de cualquiera de las clases reguladas en la Ley 11/2010, salvo aquellas que por su naturaleza sean incompatibles con la actividad cooperativizada y el objeto social de esta clase de cooperativas.

Los órganos sociales de la cooperativa rural son los previstos y regulados en la Ley 11/2010, tendiendo siempre a una participación equilibrada de hombres y mujeres. Para la adopción de acuerdos en la asamblea general, la regla general será la de que cada socio dispondrá de un voto, si bien los estatutos podrán prever un sistema de voto plural ponderado proporcional a la participación del socio en la actividad cooperativizada total de la cooperativa, con un límite máximo de cinco votos totales y sin que se pueda atribuir a un solo socio más de una cuarta parte del total de votos de la cooperativa. Si se optara como órgano de administración por un consejo rector, en éste deberán estar representadas todas las secciones de actividad de que disponga la cooperativa, en el porcentaje que estatutariamente se establezca y, como mínimo, con un consejero (art. 23).

Por último, en el capítulo IV del título III, "De las secciones", se dispone que las cooperativas rurales organizarán sus actividades en torno a las diferentes 
secciones de que disponga la entidad para gestionar las diferentes actividades económicas o sociales específicas, siendo de aplicación al funcionamiento de las mismas, salvo lo dispuesto en la Ley, el régimen legal previsto en la Ley 11/2010 y en sus estatutos. En esta línea, éstos, los estatutos sociales, deberán regular la existencia y los criterios para la constitución de secciones dentro de la cooperativa, determinando, como mínimo, los siguientes aspectos: a) Las actividades que estarán afectadas a cada sección; y b) los criterios para la medición de la actividad cooperativizada que se utilizarán, en su caso, para la distribución diferenciada de excedentes positivos y negativos de cada sección (art. 24).

Del cumplimiento de las obligaciones derivadas de la actividad de cada sección, responden en primer lugar las participaciones hechas o comprometidas y las garantías presentadas por los socios integrados en la sección o secciones, así como el patrimonio afecto a las mismas, todo ello sin perjuicio de la responsabilidad universal de la cooperativa frente a terceros (art. 25).

Tras aludir a la asamblea de las personas y entidades socias de sección (art. 26), así como al órgano de administración de las secciones (art. 27), se afirma la independencia de la contabilidad que han de llevar las secciones, sin perjuicio de la general de la cooperativa. En este sentido, las cooperativas rurales estarán obligadas a someter sus cuentas anuales a auditoría externa y a depositarlas en la unidad correspondiente del Registro de Cooperativas de Castilla-La Mancha. Además de los libros de contabilidad que resulten obligatorios, cada una de las secciones deberá llevar un libro registro de personas y entidades socias de la sección adscritos a la misma, un libro registro de las participaciones voluntarias a la sección y el libro de actas de las asambleas de personas y entidades socias de la sección (art. 28).

Finalmente, señala el artículo 29 que "la asamblea general deberá repartir los excedentes o imputar las pérdidas que resulten de la contabilidad general de la cooperativa de manera diferenciada, teniendo en cuenta el resultado económico de cada una de las secciones, de forma que los posibles retornos, imputación de pérdidas o liquidaciones de deuda que puedan corresponder a cada persona y entidad socia se efectúen teniendo en cuenta su participación en cada una de las secciones y cada una de las actividades que hubieren podido generarlos". 